http://dx.doi.org/10.1590/0370-44672019730120

\author{
Paulo Couceiro ${ }^{1}$ \\ https://orcid.org/0000-0003-2122-5228 \\ ${ }^{1}$ MAXAM Terra Solutions, Madrid - Spain. \\ paulocouceiro@gmail.com
}

\title{
Mining
}

\section{Modeling non-ideal velocity of detonation in rock blasting}

\begin{abstract}
The performance of commercial explosives is an important subject in rock blasting modeling and simulation. As a result of its non-ideal behavior, these explosives usually react below their ideal detonation velocity. In these cases, the multi-dimensional effects, heterogeneities and confinement conditions become important for properly quantifying the detonation state. In this sense, an engineering approach to model twodimensional steady non-ideal detonations for cylindrical stick explosives is used to quantify the expected detonation velocity for given reaction rate parameters and confinement conditions. Founded on an ellipsoidal shock shape approach (ESSA), the proposed model combines the quasi-one-dimensional theory for the axial solution with the unconfined sonic post-flow conditions at the edge of the explosive. A mechanistic confinement approach is coupled with the ESSA model to estimate the effect of the inert confiner on the detonation flow. Finally, the proposed model is used to estimate the expected detonation velocity of two typical commercial explosives in a number of different confinement conditions.
\end{abstract}

keywords: non-ideal detonation; confined detonation; velocity of detonation; rock blasting.

\section{Introduction}

Since the ability of modeling is inherent to any optimization strategy, a reliable explosive energy release quantification is required for a more realistic rock blasting simulation. In this regard, the interest of studying non-ideal detonations is considered to be a fundamental step for further downstream mining modeling. The explosive performance must be carried out using realistic approaches, such as those based on the Euler reactive flow analysis, and including Direct Numerical Simulations (DNS), slightly divergent flow theory, quasi-unidimensional analysis or streamline approximations, and others, rather than those based on ideal thermodynamic codes, like CHEETAH, W-DETCOM, ATLAS-Det, and others.

The detonation process in highly non-ideal explosives and its interaction with the inert confiner material is still a matter of research and discussion (Sharpe \& Braithwaite, 2005; Sharpe \& Bdzil, 2006; Sellers, 2007; Esen, 2008; Sharpe et al., 2009; Sellers et al., 2012; Braithwaite \& Sharpe, 2013). Their interaction is complex, especially in cases where the acoustic velocity of the confiner is higher than the velocity of detonation. However, when combined with a mechanistic model for the confiner material, these non-ideal detonation models can predict, within the experimental scatter levels, important properties of the detonation, such as detonation velocity, pressure, specific volume, and others.

Mining explosives are strongly dependent of blasthole diameter, densities, reaction rates, confinement and others. These characteristics require the use of some classes of non-ideal detonation models to properly quantify the explosive's performance. These methods must be able to describe the reactive flow solution of the problem, including pressure profiles, densities and others. In this sense, one practical indicator of the explosive characteristics is the detonation velocity. This election is a consequence of the relatively simple method of recording the confined in-hole detonation velocity in real scale shots. On the other hand, it is a good indicator of the explosive's non-ideality (Bilgin \& Esen, 1999) and can be normally associated with a large set of factors, such as explosive type, density, temperatures, reaction rates, blasthole diameter, confinement, primer size and many others (Sanchidrián \& Muñiz, 2000).

Thus, the prediction of the in-hole confined detonation velocity becomes particularly important to quantify the performance of a given non-ideal explosive and confinement conditions. Herein, a non-ideal detonation model based on the Ellipsoidal Shock Shape Approach (ESSA) is used to properly describe the in-hole confined detonation velocities of two different typical mining explosives in a large set of experimental and simulated data. 


\section{Governing equations}

Modeling non-ideal detonations are often based on the reactive Euler equations for the conservation of mass, momentum and energy

$$
\frac{D \rho}{D t}+\rho \nabla . \boldsymbol{u}=0 \quad \rho \frac{D \boldsymbol{u}}{D t}=-\nabla P \quad \frac{D E}{D t}-\frac{P}{\rho^{2}} \frac{D \rho}{D t}=0 \quad \frac{D \lambda}{D t}=W
$$

where $\boldsymbol{u}$ is the velocity; $\rho$ is the density; $P$ is the pressure; $E$ is the internal energy; $\lambda$ is the reaction progress $(\lambda=0$, for an unreacted product and $\lambda=1$ for a complete reaction process); and $W$ the is reaction rate, and the operator $D / D t=\partial / \partial \mathrm{t}+\boldsymbol{u} \cdot \nabla$.

The governing equations are closed by defining the equation of state $E(P, \rho$, $\lambda)$ and the reaction rate $W(P, \rho, \lambda)$. In the Detonation Shock Dynamics (DSD) theory, a change of variables is necessary to describe the behavior of the detonation process along the normal direction $n$, at any point of the shock front. Thus, the Euler reactive flow equations must be transformed from the cartesian coordinate system $(\mathrm{x}, \mathrm{y}, \mathrm{t})$ into a shock-attached coordinate system $(n, \xi, t)$. A robust mathematical foundation of this transformation is discussed elsewhere (Stewart, 1993; Yao \& Stewart,
1996; Sharpe \& Braithwaite, 2005).A typical unconfined non-ideal detonation structure is presented in Figure 1. When particularized to the axis of the charge, these equations can describe the complete axial flow solution through a unique relationship between the normal detonation velocity and axial shock curvature, constituting the basis of the quasi-one-dimensional Q1D theory (Sharpe \& Braithwaite, 2005).

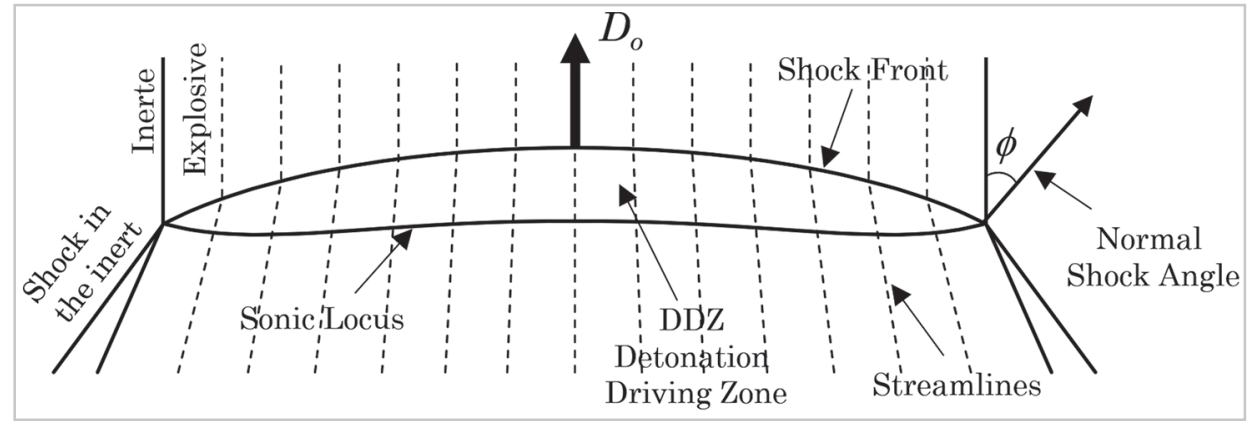

Figure 1 - Schematic representation of a typical unconfined non-ideal detonation structure. The detonation is propagating upward with a constant velocity of detonation, $D_{0}$.

\subsection{Axial flow solution}

The ESSA model requires a complete description of the axial flow solution to construct the ellipsoidal extension of the detonation shock front to the twodimensions. Although any axial solution could be used, such as those based on the slightly divergent flow theory (Kirby \& Leiper, 1985), the Q1D model (Sharpe \& Braithwaite, 2005) is adopted in this study due to its solid improvements over other axial models. One of the most important improvements is the substitution of the divergent term - which is unknown - by the axial curvature. Since its development, Q1D has been demonstrating excellent results regarding the axial flow solutions, even in highly non-ideal detonations (Sharpe et al., 2009).
The Q1D theory (Sharpe \& Braithwaite, 2005) assumes that the axial solution depends only parametrically on the detonation velocity or the shock front curvature, suggesting that it is governed by a simple $D_{n}-\kappa$ law. When combined with the quadratic pseudopolytropic equation of state (Sharpe \& Braithwaite, 2005)

$$
E=\frac{P}{\left(\gamma^{*}-1\right) \rho}-\lambda Q
$$

where $\rho$ is the density; $Q$ is the heat of reaction and the quadratic gamma $\gamma^{*}$ is given by:

$$
\gamma^{*}=\gamma_{0}+\gamma_{1} \frac{\rho}{\rho_{0}}+\gamma_{2}\left(\frac{\rho}{\rho_{0}}\right)^{2}
$$

where $\rho_{\mathrm{o}}$ is the initial density; $\gamma_{\mathrm{o}}, \gamma_{1}$ and $\gamma_{2}$ are coefficients obtained from an ideal thermo- dynamic detonation code, the following set of ordinary differential equations:

$$
\begin{gathered}
\frac{d u_{n}}{d n}=\left(\frac{1}{c^{2}-u_{n}^{2}}\right)\left[Q\left(\gamma^{*}-1\right) W+\kappa^{*} c^{2}\left(u_{n}+D_{n}\right)\right] \\
\frac{d \rho}{d n}=\left(\frac{1}{c^{2}-u_{n}^{2}}\right)\left[-Q\left(\gamma^{*}-1\right) \rho W / u_{n}+\kappa^{*} \rho u_{n}\left(u_{n}+D_{n}\right)\right] \\
\frac{d \lambda}{d n}=\frac{W}{u_{n}}
\end{gathered}
$$


can be obtained. Where $u_{n}$ is the normal particle velocity; $\rho$ is the density; $D_{n}$ is the normal velocity of detonation; $c$ is the sound speed; $Q$ is the heat of explosion; $\gamma$ is the adiabatic

$$
W=\frac{1}{\tau}(1-\lambda)^{m}\left(\frac{P}{P_{\text {ref }}}\right)^{n}
$$

where $n, m$ and $\tau$ are fitting parameters; $P_{\text {ref }}$ is a reference pressure. This type of pressure-based reaction rate law presents a maximum at the shock (Cartwright, 2016). gamma; $\kappa^{*}=\kappa(1+n \kappa)^{-1} ;$ and $W$ is the reaction rate, given by a pressure dependent equation

$$
c^{2}=\left[\frac{P}{\rho^{2}}-\frac{\partial E}{\partial \rho}\right]\left(\frac{\partial E}{\partial \rho}\right)^{-1}=P\left[\frac{\gamma^{*}}{\rho}+\frac{1}{\gamma^{*}-1}\left(\gamma_{1} \frac{1}{\rho_{0}}+2 \gamma_{2} \frac{\rho}{\rho_{0}^{2}}\right)\right]
$$

where $\rho=1 / \mathrm{v}$.

Depending of the "form" of the reaction rate equation, the number of

by assuming the strong shock approximation.

Thus, the set of ordinary differential Equations (4), (5) and (6) form a differential equations needed to solve the problem can be reduced. In this article, since $W$ is dependent on the pres-

$$
P=\frac{\left(\gamma^{*}-1\right) \rho}{\gamma^{*}}\left[\frac{D_{n}^{2}-u_{n}^{2}}{2}+Q \lambda\right]
$$

boundary-value problem, in other words, an eigenvalue problem in $\kappa\left(D_{n}\right)$ for a given $D_{n}(\kappa)$. The most common resolution method is the shooting method, subjected sure, and consequently on the specific density or volume, the pressure can be expressed as

to the jump shock conditions at the shock front and generalized CJ conditions at the sonic locus (Stewart \& Yao, 1998; Sharpe, 2000; Sharpe \& Braithwaite, 2005).

\section{Ellipsoidal shock shape approach}

In the case of a highly non-ideal detonation, experimental shock measurements indicate that the detonation shock front can be well represented by an elliptic arc (Kennedy, 1998; Sharpe \& Braithwaite,

can be assumed to well represent the shock shape. Here, $z$ and $r$ are the axial and radial directions, respectively; and $\alpha$ and $\beta$ are the semi-minor and semi-major axis
2005). This observation is also supported by Direct Numerical Simulations (DNS). Additionally, Watt et al., (2009), using the Maximum Effective Entropy Theory (Byers Brown, 2002) in the construction

$$
\frac{\left(z_{f}+\alpha\right)^{2}}{\alpha^{2}}+\frac{r^{2}}{\beta^{2}}=1
$$

of the ellipse. In this study, the semi-axis of the ellipse is called shock shape parameters. The origin of the adopted coordinate system is located at the central axis of the

\subsection{Two-dimension model expansion}

There is a unique relationship between the axial flow solution, shock shape parameters and radial dimension of the charge. Since the axisymmetric curvature $\kappa$ is the solution of the set of differential Equations (4), (5) and (6) for a given velocity of detonation $D_{n}$

which relates the axial solution with the shock shape parameters.

Once the interdependence between the shock shape parameters and and reaction rate parameters $n, m$ and $\tau$, a further relationship between $\kappa$, $\alpha$ and $\beta$ can be addressed in order to ensure a proper dependence between the shock shape parameters and axial solution. This is a necessary condition for the problem.

$$
\beta=\left(\frac{2 \alpha}{\kappa_{a x i s}}\right)^{1 / 2}
$$

axial solution is established, the first boundary condition at the edge of the unconfined charge can be defined in terms of the shock slope. This condi-

$$
z_{f}^{\prime}(r=R)=-\left(\frac{\gamma-1}{\gamma+1}\right)^{1 / 2}
$$

of the detonation driving zone (DDZ), obtained better results when an ellipsoidal shock shape function was used to represent the detonation shock front. These evidences suggest that an ellipse of the form

shock front, where $r=0$ and $z=0$. An assumed shock shape function allows one to calculate the slope angle and curvature $\kappa$ at any point along of the shock $z_{f}$

The shock front shape function $z_{f}$ can be differentiated twice in order to express the curvature at any point along of the shock. Thus, at $r=0, z_{f}^{\prime \prime}$ can be related to the axisymmetric cylinder shock front curvature $\kappa_{a x i s}$ by the following expression

tion establishes that the post-shock flow must be exactly sonic at the charge edge, $r=R$ (Cartwright, 2016). That is, given by the shock polar analysis as: 
where $\mathrm{R}$ is the charge radius, $z_{f}^{\prime}=d z / d r$ and $\gamma$ is the polytropic gamma. Thus, the first derivate of Equation (10) must be equal to (12) in order to comply with the first boundary condition.

However, under an ellipsoidal shock shape hypothesis, many possible sonic solutions could be found at different charge radii, if Equation (12) is the only boundary condition. Consequently, in order to calculate the

where $\lambda$ is the reaction progress at the axis; $m$ is a reaction rate parameter; $D_{o}$ is the velocity of detonation; and $D_{g}$ is the thermodynamic ideal velocity of detonation; $f_{a}$ is a function dependent on the pressure and adiabatic coefficient.

\subsection{Confined detonation}

The strategy adopted in the present article is based on the ideas initially proposed by Eyring et al., (1949) and continued by Souers et al., (2004). A simple inspection of the diameter-effect curves resulting

where $f_{c}$ is the confinement factor; $R_{u}$ and $R_{c}$ are the unconfined and confined radius, respectively.

Sellers (2007) observed the impor-

where $\rho_{c}$ and $C_{c}$ are the density and acoustic velocity of the confining material; $\rho_{o}$ and $D_{o}$ are the density and detonation velocity of the explosive;

\section{Results and discussion}

In order to explore some features of the ESSA model and its potential application in rock blasting simulations, several detonation cases were modeled to observe the influence of different explosives, rock confinements and blasthole diameters charge radius, an additional second and complementary boundary condition must be formulated by considering the interdependence of the shock shape parameters and axial solution.

Exploring the ellipsoidal structure of the problem, for a given set of shock shape parameters, it is expected to find a charge radius $R$ smaller than the semi-major axis of the ellipse $z_{f}$, so that $R_{\max }=\beta$. Hence, a relationship between

$$
f_{n}=1-f_{a}\left[(1-\lambda)^{\mathrm{m}} \frac{D_{0}}{D_{\mathrm{CJ}}}\right]
$$

Thus, both the charge radius $R$ and velocity of detonation $D_{0}$ can be related to the shock shape parameters by combining the Equations (10), (11), (12) and (13). From these equations, one can observe how $R$ increases when $D_{o}$ and $\lambda$ increases. In the limit

from unconfined and confined detonations reveals that for a given diameter, the detonation velocity increases as the confinement increases. Similarly, for a given detonation velocity, it shows how the charge radius

$$
\frac{R_{\mathrm{u}}}{R_{\mathrm{c}}}=f_{c}
$$

tance of the elastic parameters of the confining material and its effect on the confined detonation velocity. It is expected that $f_{c}$ be proportional to the constitutive

$$
f_{c}=\left[1+\frac{1}{f_{z}} \frac{\rho_{c} C_{c}}{\rho_{0} D_{o}}\right]^{\frac{C_{c}}{D_{0}}}
$$

$f_{z}$ is the artificial pre-compression factor due to the subsonic coupling $\left(f_{z}=1\right.$ for supersonic; and $f_{z}>1$ for subsonic). In the case of rock blasting dimen-

upon the degree of the detonation velocity. The evaluation is centered on the performance of two different explosives, an ANFO (Kirby et al., 2014) and blended Emulsion 70/30 (Sujansky \& Noy, 2000), covering blasthole diameters from $165 \mathrm{~mm}$ to the unconfined charge radius and the semi-major axis of the ellipse can be established as $f_{n}=R / R_{\max }$, where $f_{n}$ is an expression which relates to the degree of non-ideality of the explosive. Comparable to other relationships such as $D_{o} / D_{C}$ or $\lambda$, the $R / R_{\text {max }}$ ratio should present a similar behavior when the detonation approaches its ideal performance. Thus, $f_{n}$ is defined as a dimensionless expression of the following form

case, when the detonation approaches to its ideal behavior $\lambda \rightarrow 1$ and $D_{o} \rightarrow D_{C}$, we have that $R \rightarrow R_{\text {max }}$. This behavior is in line with Sharpe \& Braithwaite (2005) findings about how the shock locus becomes flatter at the axis when the detonation speed increases.

decreases when the confinement increases. Thus, once the unconfined detonation state is known, the equivalent confined state is found to be dependent on the confinement, which leads to

properties and thickness of the confining material. Thus, the proposed confinement factor incorporates important features of the problem

sions, the confining thickness is far bigger than the critical thickness, corresponding to the case of infinite thickness confinement.

$311 \mathrm{~mm}$. The properties of the different rock masses, where several in-hole detonation velocities were measured, are presented in Table 1. These data were presented by Esen (2008) as part of the DeNE code validation study. 
Table 1 - Rock properties (Esen, 2008).

\begin{tabular}{c|c|c|c|c}
\hline Rock type & Density & Seismic velocity & Young's Modulus & Poisson \\
\hline Breccia & $2750 \mathrm{~kg} / \mathrm{m}^{3}$ & $6320 \mathrm{~m} / \mathrm{s}$ & $51.4 \mathrm{GPa}$ & 0.30 \\
\hline Sandstone & $2500 \mathrm{~kg} / \mathrm{m}^{3}$ & $4326 \mathrm{~m} / \mathrm{s}$ & $29.7 \mathrm{GPa}$ & 0.35 \\
\hline Overburden & $1900 \mathrm{~kg} / \mathrm{m}^{3}$ & $2598 \mathrm{~m} / \mathrm{s}$ & $12.3 \mathrm{GPa}$ & 013 \\
\hline Copper ore & $2970 \mathrm{~kg} / \mathrm{m}^{3}$ & $5455 \mathrm{~m} / \mathrm{s}$ & $55.0 \mathrm{GPa}$ & 0.35 \\
\hline Kimberlite & $2264 \mathrm{~kg} / \mathrm{m}^{3}$ & $2521 \mathrm{~m} / \mathrm{s}$ & $11.0 \mathrm{GPa}$ & 0.28 \\
\hline Kimberlite (TKB) & $2520 \mathrm{~kg} / \mathrm{m}^{3}$ & $3945 \mathrm{~m} / \mathrm{s}$ & $25.0 \mathrm{GPa}$ & 0.35 \\
\hline Monzonite (Cadia Extension) & $2693 \mathrm{~kg} / \mathrm{m}^{3}$ & $5023 \mathrm{~m} / \mathrm{s}$ & $49.6 \mathrm{GPa}$ & 0.31 \\
\hline Monzonite (610/625m Level) & $2706 \mathrm{~kg} / \mathrm{m}^{3}$ & $4658 \mathrm{~m} / \mathrm{s}$ & $43.7 \mathrm{GPa}$ & 0.30 \\
\hline Fresh Volvanics (North Wall) & $2654 \mathrm{~kg} / \mathrm{m}^{3}$ & $4480 \mathrm{~m} / \mathrm{s}$ & $40.9 \mathrm{GPa}$ & 0.29 \\
\hline East Porphyry & $2520 \mathrm{~kg} / \mathrm{m}^{3}$ & $2430 \mathrm{~m} / \mathrm{s}$ & $11.3 \mathrm{GPa}$ & 0.29 \\
\hline
\end{tabular}

\subsection{Explosive characterization}

Before proceeding with the confined detonation cases, it is necessary to characterize the explosives involved in the study. In the ESSA model, and in most of non-ideal detonation approaches, the characterization is normally carried out in two parts.

The first step is the thermody- namic characterization of such explosive, which includes its ideal detonation velocity, heat of explosion and the quadratic coefficients of the isentropic gamma. These parameters are calculated with ideal thermodynamic codes, such as IDEX and ATLAS-Det, and are presented in Table 2. The ANFO ideal detonation velocity is taken from Sharpe \& Braithwaite (2005), together with other parameters, such as the heat of explosion and the coefficients of the quadratic gamma function. The thermodynamic description of the EM $70 / 30$ was calculated with the ATLASDet code (Couceiro, 2019).

Table 2 - Ideal thermodynamic data.

\begin{tabular}{c|c|c|c|c|c|c}
\hline Explosive & $D_{C J}(\mathrm{~m} / \mathrm{s})$ & $\rho_{0}\left(\mathrm{~kg} / \mathrm{m}^{3}\right)$ & $Q(\mathrm{~kJ} / \mathrm{kg})$ & $\gamma_{0}$ & $\gamma_{1}$ & $\gamma_{2}$ \\
\hline ANFO & 4800 & 800 & 3822 & 1.3333 & 0.36264 & 0.076288 \\
\hline EM 70/30 & 6648 & 1230 & 2705 & 1.4053 & 0.77030 & 0.705634 \\
\hline
\end{tabular}

The second step is quantification of their non-ideality behavior. Since these ammonium nitrate-based materials are non-ideal explosives, multi-dimensional effects and mixing heterogeneities become extremely important to properly quantify their detonation performance, which requires some knowledge about their reaction kinetics. The chemical reaction rate is not known analytically and requires the calibration of the reaction rate parameters against a set of unconfined detonation velocities, distributed in a set of different diameters.

The ESSA model presents an attractive fitting capability for unconfined detonation data. This is possible, since it is coupled with the Q1D model (Sharpe \& Braithwaite, 2005) for the axial flow solution. The fitting process can be performed when experimental data-diameters and unconfined detonation velocities - are available. In this study, the ANFO data set is obtained from Kirby et al. (2014) while the EM $70 / 30$ is coming from Sujansky \& Noy (2000). The fitting strategy is straightforward. It consists in minimizing the sum of residues formed by the square of the difference between the experimental and calculated inverseradius of the charges by varying the reaction rate parameters $n, m$ and $\tau$. Thus, once both sets of information are available, the ESSA model can reliably reproduce the structure of any unconfined detonation within the set of experimental diameters, including the full mapping of the diametereffect curve of the explosive.

The values of $n, m$ and $\tau$ resulting from the minimization process are presented in Table 3. In addition, it is noted that a weaker state dependency was required to experimentally adjust both explosives, since $n=1.78$ and $n=5.77$ were obtained.
Cowperthwaite (1994) was the first to observe the existence of an inflection point in diameter-effect curves when $n \geq 1.5$ (Watt, et al., 2012; Cartwright, 2016). Figure 2 shows the modeled diameter-effect curves for the ANFO and EM 70/30 together with the experimental data (Kirby et al., 2014; Sujansky \& Noy, 2000). The presence of an inflection point is evident in both curves. In the ANFO case, it indicates a critical diameter of $78.8 \mathrm{~mm}$, which is very close to the critical experimental diameter of $79 \mathrm{~mm}$. On the other hand, the EM $70 / 30$ experimental data suggest a critical diameter less than $40 \mathrm{~mm}$. In turn, the ESSA model identifies a critical diameter of $36 \mathrm{~mm}$, in perfect coherence with the experimental data. It is further noted that as the diameters increase, the non-ideal detonation velocities approximate to the ideal detonation velocity, as expected. 


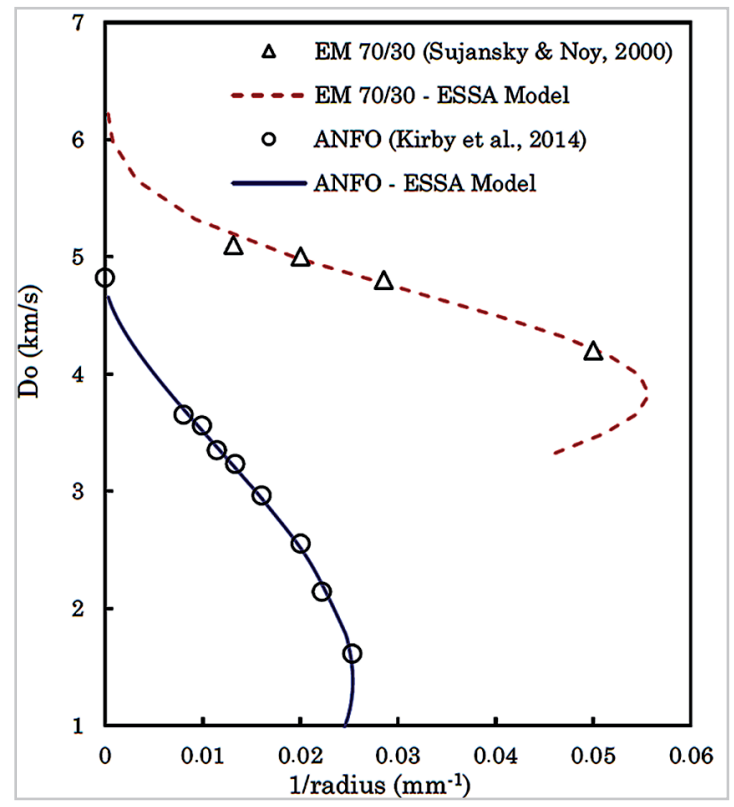

Figure 2 - Modelled and experimental unconfined diameter-effect curves from ANFO and EM 70/30.

Table 3 - Reaction rate parameters.

\begin{tabular}{c|c|c}
\hline Explosive & ANFO & EM 70/30 \\
\hline Initial density & $800 \mathrm{~kg} / \mathrm{m}^{3}$ & $1230 \mathrm{~kg} / \mathrm{m}^{3}$ \\
\hline$D_{C J}$ & $4800 \mathrm{~m} / \mathrm{s}$ & $6648 \mathrm{~m} / \mathrm{s}$ \\
\hline$m$ & 2.19 & 16.27 \\
\hline$n$ & 1.78 & 5.77 \\
\hline$\tau$ & $2.82(-05)$ & $2.45(-04)$ \\
\hline
\end{tabular}

\subsection{ESSA model application in rock blasting}

Since the reproduction of real-scale detonation experiments in the laboratory are restrictive, the validation of non-ideal detonation models is normally carried out against experimental in-hole detonation velocity taken in production blasts. In real applications, the detonation velocity can be a good indicator of the degree of nonideality of a given explosive. In this study, a set of published in-hole detonation velocities (Esen, 2008), together with results obtained with DeNE code, were used to compare the prediction capability of the ESSA model. The DeNE code, developed by Esen (2008), is based on the slightly divergent flow theory, combining the pseudo-polytropic equation of state, pressure-based reaction rate law and statistical expressions to model the effect of confinement.

Thus, the ESSA model was applied in similar circumstances of application, such as blasthole diameters, rock types and explosive properties as defined by Esen (2008). The corresponding in-hole confined velocities of detonation and their comparison with the experimental and DeNE values were evaluated. The results are presented in Table 4.

Table 4 - Comparison between experimental and predicted detonation velocities.

\begin{tabular}{|c|c|c|c|c|c|c|}
\hline \multirow{2}{*}{ Explosive } & \multirow{2}{*}{ Rock } & \multirow{2}{*}{$d(\mathrm{~mm})$} & \multirow{2}{*}{$\rho\left(\mathrm{kg} / \mathrm{m}^{3}\right)$} & \multicolumn{3}{|c|}{$D(\mathrm{~m} / \mathrm{s})$} \\
\hline & & & & Exp. & DeNE & ESSA \\
\hline $\mathrm{ANFO}^{(1)(3)}$ & Breccia & 169 & 800 & 4235 & 4058 & 4245 \\
\hline $\mathrm{ANFO}^{(1)(3)}$ & Sandstone & 269 & 800 & 4220 & 4408 & 4384 \\
\hline $\mathrm{ANFO}^{(1)(3)}$ & Overburden & 311 & 800 & 4370 & 4453 & 4156 \\
\hline $\mathrm{ANFO}^{(2)(3)}$ & Copper ore & 165 & 800 & 4380 & 4024 & 4269 \\
\hline Blend $1^{(3)}$ & Kimberlite & 165 & 1050 & 5079 & 5210 & 4959 \\
\hline Blend $1^{(3)}$ & Kimberlite (TKB) & 165 & 1050 & 5159 & 5297 & 5149 \\
\hline Blend $2^{(3)}$ & Monzonite (Cadia Extension) & 210 & 1120 & 5728 & 5774 & 5489 \\
\hline Blend $2^{(3)}$ & Monzonite $(610 / 625 \mathrm{~m}$ Level) & 222 & 1120 & 5460 & 5805 & 5471 \\
\hline Blend $2^{(3)}$ & Fresh Volcanic (North Wall) & 210 & 1120 & 5479 & 5765 & 5433 \\
\hline Blend $3^{(3)}$ & East Porphyry & 311 & 1290 & 5864 & 5993 & 5613 \\
\hline
\end{tabular}

(1) Sarma, 1998; (2) Gill, 1995; (3) Esen, 2008. 
According to Esen (2008), the mean error in the experimental measurements was $3.5 \%$, presenting a variation between $2.2 \%$ and $7.2 \%$. As can be seen in Table 4 , the results achieved with the ESSA model were very good, presenting errors consistent with the experimental tests. The total mean error of the ESSA model was $2.4 \%$ while the DeNE was $3.8 \%$, as presented in Table 5 . Analyzing by groups of explosives, the simulations with DeNE for the ANFO showed an average error of $4.7 \%$, while ESSA was $2.9 \%$. For the blended emulsion, the errors were $3.3 \%$ and $2.0 \%$, respectively.

The ESSA model shows a good response to the sensitivities imposed by different confinement conditions. This sensitivity characteristic is important to obtain a reliable prediction of the in- hole detonation velocity, and the fully axial reactive flow solution, in a sort of conditions where commercial explosives are normally applied. Thus, since the observed errors - shown in Table 5 - are within the range of experimental errors presented by Esen (2008), it is believed that the ESSA model is adequate for its practical application in rock blasting simulation and modeling.

Table 5 - Comparison between experimental and predicted detonation velocities.

\begin{tabular}{|c|c|c|c|c|c|}
\hline \multirow{2}{*}{ Explosive } & \multirow{2}{*}{ Rock } & \multicolumn{2}{|c|}{ Error \% } & \multicolumn{2}{|c|}{ Error \% } \\
\hline & & DeNE & Average Error & ESSA & Average Error \\
\hline ANFO & Breccia & $-4.2 \%$ & \multirow{4}{*}{$4.7 \%$} & $0.2 \%$ & \multirow{4}{*}{$2.9 \%$} \\
\hline ANFO & Sandstone & $4.5 \%$ & & $3.9 \%$ & \\
\hline ANFO & Overburden & $1.9 \%$ & & $-4.9 \%$ & \\
\hline ANFO & Copper ore & $-8.1 \%$ & & $-2.5 \%$ & \\
\hline Blend 1 & Kimberlite & $2.6 \%$ & \multirow{6}{*}{$3.3 \%$} & $-2.4 \%$ & \multirow{6}{*}{$2.0 \%$} \\
\hline Blend 1 & Kimberlite (TKB) & $2.7 \%$ & & $-0.2 \%$ & \\
\hline Blend 2 & Monzonite (Cadia Extension) & $0.8 \%$ & & $-4.2 \%$ & \\
\hline Blend 2 & Monzonite (610/625m Level) & $6.3 \%$ & & $0.2 \%$ & \\
\hline Blend 2 & Fresh Volcanic (North Wall) & $5.2 \%$ & & $-0.8 \%$ & \\
\hline Blend 3 & East Porphyry & $2.2 \%$ & & $-4.3 \%$ & \\
\hline & Average total absolute error & $3.8 \%$ & & $2.4 \%$ & \\
\hline
\end{tabular}

\section{Conclusions}

A two-dimensional steady nonideal detonation model based on the Ellipsoidal Shock Shape Approach (ESSA) was successfully used to predict the in-hole detonation velocity under several confinement conditions. Once the reaction rate parameters were fitted, the ESSA model could provide an excellent prediction of the unconfined diametereffect curves for both ANFO and EM 70/30 explosives, including their failure diameters. The experimental in-hole detonation velocity data was presented alongside with the predictions of the DeNE (Esen, 2008) and compared with the ESSA model outcomes. The overall results indicate a better response of the proposed model to the different confinement conditions, explosives types and blasthole diameters, within the set of analyzed experimental data, endowing the ESSA model as a reliable information source for a more realistic rock blasting analysis and simulation.

\section{References}

BILGIN, H. A.; ESEN, S. Assessment of ideality of some commercial explosives. In: ANNUAL CONFERENCE ON EXPLOSIVES \& BLASTING TECHNIQUE, 25., 1999, Nashville, Tennessee, USA. Proceedings [...]. Nashville: ISEE, 1999. p. 35-44.

BRAITHWAITE, M.; SHARPE, G. J. Non-ideal detonation behavior in commercial explosives. In: ROCK FRAGMENTATION BY BLASTING: FRAGBLAST, 10., 2013, New Delhi, India. Proceedings [...]. New Delhi: CRC Press, 2013. p. 11-16.

BYERS BROWN, W. Critical review of theories of steady non-ideal two-dimensional detonation of condensed explosives. Review report for the Hybrid Stress Blast Model Project. United Kingdom: Hybrid Stress Blast Model Project, 2002.

CARTWRIGHT, M. Modelling of non-ideal steady detonations. 2016. $188 \mathrm{f}$. Thesis (PhD) - Department of Applied Mathematics, University of Leeds, Leeds, United Kingdom, 2016.

COUCEIRO JUNIOR, P. J. C. Modelagem de detonações não-ideais e sua influência nas fenomenologias associadas aos desmontes de rochas com explosivos. 2019. 210f. Tese (Doutorado em Engenharia de Minas e Geo-Recursos) - Faculdade de Engenharia, Universidade do Porto, Porto, Portugal, 2019.

ESEN, S. A statistical approach to predict the effect of confinement on the detonation velocity of commercial explosives. Rock Mechanics and Rock Engineering, Austria, v. 37, n. 4, p. 317-330, 2004. DOI: https://doi. org/10.1007/s00603-004-0026-3.

ESEN, S. A Non-ideal detonation model for evaluating the performance of explosives in rock blasting. Rock 
Mechanics and Rock Engineering, Netherlands, v. 41, n. 3, p. 467-497, 2008. DOI 10.1007/s00603-006-0119-2. EYRING, H.; POWELL, R. E.; DUFFEY, G. H.; PARLIN, R. B. The stability of detonation. Chemical Reviews, v. 45, n. 1, p. 69-181, 1949. DOI: https://doi.org/10.1021/cr60140a002.

GILL, M. D. Explosive/rock interaction in an underground mine. In: EXPLO' 95 CONFERENCE, 1995, Australia, Brisbane. Proceedings [...]. Brisbane: Carlton, Vic., 1995. p. 51-62.

KENNEDY, D. L. Multi-valued normal shock velocity versus curvature relationships for highly non-ideal explosives. In:SYMPOSIUM (INTERNATIONAL) ON DETONATION, 11., 1998, Snowmass, Colorado. Proceedings [...]. Snowmass: Office of Naval Research, 1998. p. 181-192.

KIRBY, I. J.; LEIPER, G. A. A small divergent detonation theory for intermolecular explosives. In: SYMPOSIUM (INTERNATIONAL) ON DETONATION, 8., 1985, Albuquerque, New Mexico, USA. Proceedings [...]. Albuquerque: Office of Naval Research, 1985. p. 176-186.

KIRBY, I.; CHAN, J.; MINCHINTON, A. Advances in predicting the effects of non-ideal detonation on blasting. In: ANNUAL CONFERENCE ON EXPLOSIVES AND BLASTING TECHNIQUE, 40., 2014, Denver, Colorado, USA. Proceedings [...]. Denver: ISEE, 2014. p. 1-14.

SANCHIDRIÁN, J. A.; MUÑIZ, E. Curso de tecnología de explosivos. Madrid: Fundación Gómez Pardo, 2000.

SARMA, K. S. Models for assessing the blasting performance of explosives. 1998. $224 \mathrm{f}$. Thesis (PhD) - School of Engineering, The University of Queensland, Brisbane, Australia, 1998.

SELLERS, E. J. Velocity of detonation of non-ideal explosives: investigating the influence of confinement. In: ANNUAL CONFERENCE ON EXPLOSIVES AND BLASTING TECHNIQUE, 33., 2007, Nashville, Tennessee, USA. Proceedings [...]. Nashville: ISEE, 2007. p. 1-11.

SELLERS, E.; FURTNEY, J.; ONEDERRA, I.; CHITOMBO, G. Improved understanding of explosive-rock interactions using the hybrid stress blasting model. The Journal of the Southern African Institute of Mining and Metallurgy, Johannesburg, v. 112, n. 8, 2012.

SHARPE, G. The structure of planar and curved detonation waves with reversible reactions. Physics of Fluids, v. 12, n. 11, p. 3007-3020, 2000. DOI: https://doi.org/10.1063/1.1313389.

SHARPE, G. J.; BDZIL, J. B. Interactions of inert confiners with explosives. Journal of Engineering Mathematics, v. 54, n. 3, p. 273-298, 2006. DOI: https://doi.org/10.1007/s10665-005-9025-y.

SHARPE, G. J.; BRAITHWAITE, M. Steady non-ideal detonations in cylindrical sticks of explosives. Journal of Engineering Mathematics, v. 53, n. 1, p. 29-58, 2005. DOI: https://doi.org/10.1007/s10665-005-5570-7.

SHARPE, G. J.; LUHESHI, M. Y.; BRAITHWAITE, M.; FALLE, S. A. Steady non-ideal detonation. In: APS TOPICAL CONFERENCE SHOCK COMPRESSION OF CONDENSED MATTER, 16., 2009, Nashville, Tennessee, USA. Proceedings [...]. Nashville: American Institute of Physics, 2009. p. 452-457. DOI: https://doi. org/10.1063/1.3295171.

SHORT, M.; QUIRK, J. J. High explosive detonation-confiner interactions. Annual Review of Fluid Mechanics, v. 50, p. 215-242, 2018. DOI: https://doi.org/10.1146/annurev-fluid-122316-045011.

SHORT, M.; ANGUELOVA, I. I.; ASLAM, T. D.; BDZIL, J. B.; HENRICK, A. K.; SHARPE, G. J. Stability of detonations for an idealized condensed-phase model. Journal of Fluid Mechanics, v. 595, p. 45-82, 2008. DOI: https:// doi.org/10.1017/S0022112007008750.

SOUERS, P. C.; VITELLO, P.; ESEN, S.; BILGIN, H. A. The effects of containment on detonation velocity. Propellants, Explosives, Pyrotechnics, v. 29, n. 1, p. 16-26, 2004. DOI: https://doi.org/10.1002/prep.200400028.

STEWART, D. S.; YAO, J. The normal detonation shock velocity-curvature relationship for materials with nonideal equation of state and multiple turning points. Combustion and Flame, v. 113, n. 1/2, p. 224-235, 1998.

STEWART, S. Lectures on detonation physics: introduction to the theory of detonation shock dynamics. Illinois: The University of Illinois, 1993. (Report Number WL-TR-94-7089).

SUJANSKY, V.; NOY, M. Emulsion explosive. Applicant: Orica Explosives Technology Pty Ltd. WO 00/78694 A1. Applied: 16 June 2000.

WATT, S. D.; SHARPE, G. J.; FALLE, S. A.; BRAITHWAITE, M. A streamline approach to two-dimensional steady non-ideal detonation: the straight streamline approximation. Journal of Engineering Mathematics, v. 75, n. 1, pp. 1-14, 2012. DOI: https://doi.org/10.1007/s10665-011-9506-0.

WATT, W.; BRAITHWAITE, M.; BYERS BROWN, W.; FALLE, S.; SHARPE, G. Maximum entropy of effective reaction theory of steady non-ideal detonation. In: APS TOPICAL CONFERENCE ON SHOCK COMPRESSION OF CONDENSED MATTER, 16., 2009, Nashville, Tennessee, USA. Proceedings [...]. Nashville: American Physical Society, 2009. p. 213-216. DOI: http://dx.doi.org/10.1063/1.3295106.

YAO, J.; STEWART, D. S. On the dynamics of multi-dimensional detonation. Journal of Fluid Mechanics, v. 309, p. 225-215, 1996. DOI: https://doi.org/10.1017/S0022112096001620.

Received: 17 August 2019 - Accepted: 19 February 2020.

All content of the journal, except where identified, is licensed under a Creative Commons attribution-type BY. 